\title{
Gas-mediated liquid metal printing toward large-scale 2D semiconductors and ultraviolet photodetector
}

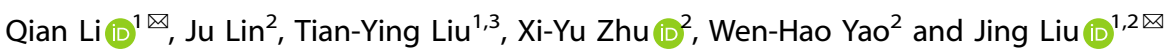

A gas-mediated fabrication of centimeter-scale two-dimensional (2D) semiconductors and ultraviolet photodetector by a liquid metal-based printing was reported. Various large-scale $2 \mathrm{D}$ materials $\left(\mathrm{Ga}_{2} \mathrm{O}_{3}, \ln _{2} \mathrm{O}_{3}, \mathrm{SnO}\right)$ were demonstrated to be directly printed at ambient air on different substrates. Such printing represents a generic, fast, clean, and scalable technique to quickly manufacture 2D semiconductors. The electrical properties were explored to quantify the printed 2D films, which were somewhat deficient in previous studies. In particular, to explore and facilitate the advantages of this 2D semiconductor in functional electronic applications, strategies for realizing fully printed $\mathrm{Ga}_{2} \mathrm{O}_{3} / \mathrm{Si}$ heterojunction photodetector via low-temperature and lowcost processes were developed. The device exhibits excellent sensibility and rapid photoresponse times. This work offers feasible way to develop high-performance ultraviolet photodetector for mass production. It also suggests a promising direction for making large-scale 2D photoelectronic and electronic systems and is expected to be extensively useful in the coming time.

npj 2D Materials and Applications (2021)5:36; https://doi.org/10.1038/s41699-021-00219-y

\section{INTRODUCTION}

Two-dimensional semiconductors with good vectors mobility as well as excellent mechanical features are ideal materials for modern generation electronics, especially for flexible electronics, extensive area, and optoelectronics. However, large-scale production of low-cost flexible electronic products requires a simple and effective strategy of deposition and patterning of these materials ${ }^{1}$. Up to now, several methods have been demonstrated to separate and synthesize two-dimensional materials. The simplest method is to mechanically remove the atomic sheets from the lamellar crystal with tape ${ }^{2}$. This allows high crystallinity flakes to be made, but the yield is pretty low. In addition, these sheets are irregular in shape and only tens of microns in length, so they are not appropriate for practical use in large-scale. Chemical vapor deposition $^{3}$ and metal-organic chemical vapor deposition $(\mathrm{MOCVD})^{4}$ have made great progress as a method for large area growth of two-dimensional material samples. In these approaches, one or more volatile precursors are utilized in order to decompose or react above the surface of the layers to deposit the required materials. The aforementioned approaches allow materials to grow on a rigid substrate including sapphire and silica, with an area of about tens of square centimeters. But these processes need almost high temperatures (above $550^{\circ} \mathrm{C}$ ), that limits the growth on polymer substrates with high flexibility. In addition, the long growth time entailed (around $26 \mathrm{~h}$ for centimeter-scale MOCVD growth) is a pervasive problem for manufacturing on mass scale.

Liquid metals have numerous interesting surface and bulk properties, which have attracted great attention in various engineering applications, including microfluidic components ${ }^{5}$, sensors $^{6}$, electrodes ${ }^{7}$, transistors ${ }^{8}$, flexible and scalable systems ${ }^{9}$, disease therapy ${ }^{10}$, and biomedical area ${ }^{11}$. In particular, under atmospheric conditions, liquid metal displays a naturally formed atomic thin oxide layer on its interface. This kind of metal oxide can adhere well to other oxides (such as silicon dioxide and silicon) which are usually used as substrates of electronic devices, but the parent metal in a liquid state cannot. It has been gradually realized that liquid metals have a wide melting range and can form a variety of alloys. Furthermore, the skin of the alloys can be adjusted, which brings opportunities for the preparation of various 2D films. By contacting the liquid metal droplet with the target substrate, various binary metal oxide thin sheets, such as $\mathrm{Ga}_{2} \mathrm{O}_{3}{ }^{12}$, $\mathrm{Bi}_{2} \mathrm{O}_{3}{ }^{13}, \mathrm{SnO}^{14}$, and $\mathrm{SnO}_{2}{ }^{15}$, can be obtained by using the skin of the liquid metal. Some studies further found that the surface oxides formed on the In-Sn alloy contain In and Sn with a ratio similar to that of indium tin oxide (ITO). Therefore, by stripping the surface of this alloy, wafer-scale ITO sheets with thicknesses of only a few atoms were successfully prepared ${ }^{16}$. In addition, through the post-processing steps, the skin of liquid metal can also be used to manufacture other $2 \mathrm{D}$ films, such as $\mathrm{GaPO}_{4}{ }^{17}$, $\mathrm{GaN}^{18}, \mathrm{GaS}^{19}$, and $\mathrm{Ga}_{2} \mathrm{~S}_{3}{ }^{20}$, and microscale $2 \mathrm{D}$ single crystals, such as $\mathrm{Mo}_{2} \mathrm{GaC}^{21}, \mathrm{GaN}^{22}$, whether they are essentially layered or non layered materials. Moreover, transition metal oxides $\left(\mathrm{HfO}_{2}\right)$, posttransition metal oxides $\left(\mathrm{Al}_{2} \mathrm{O}_{3}\right)$, and rare earth metal oxides $\left(\mathrm{Gd}_{2} \mathrm{O}_{3}\right)$ can also be prepared on the surface of liquid metal alloy by alloying $\mathrm{HF}, \mathrm{Al}$, and $\mathrm{Gd}$ with galinston, respectively ${ }^{23}$. However, the characterization of electrical properties of these 2D oxide films is still scarce, and there are few reports on the fabrication of semiconductor functional devices using $2 \mathrm{D}$ oxide films.

In this article, different to conventional techniques, we report the fully printed ultraviolet (UV) solar-blind photodetector based on printed 2D oxide films and $\mathrm{Si}$ heterojunction. In order to prepare two-dimensional oxide films suitable for optoelectronic devices, we adopted low-temperature printing technology of wafer-scale 2D semiconductor films. Through melting metal on substrates and scraping printing the metal, we are able to transfer a slim layer of metal oxide onto the target layers. This technique works just like the process of applying ink to paper or fabric in printing of screen. Using such print technology, we have manufactured large-scale high-quality 2D semiconductor films

\footnotetext{
${ }^{1}$ Beijing Key Lab of Cryo-Biomedical Engineering and Key Lab of Cryogenics, Technical Institute of Physics and Chemistry, Chinese Academy of Sciences, Beijing, PR China. ${ }^{2}$ Department of Biomedical Engineering, School of Medicine, Tsinghua University, Beijing, PR China. ${ }^{3}$ School of Engineering Science, University of Chinese Academy of Sciences, Beijing, PR China. ${ }^{凶}$ email: liqian@mail.ipc.ac.cn; jliu@mail.ipc.ac.cn
} 
on different substrates. A series of characterizations of printed 2D semiconductor materials were carried out, especially the electrical properties and optical absorption properties which were insufficient in previous studies. Furthermore, we analyzed and explored three kinds of printed $2 \mathrm{D}$ semiconductor, and chose $\mathrm{Ga}_{2} \mathrm{O}_{3}$ with the best light absorption characteristics to construct ultraviolet photoelectric devices. Different from traditional and conventional techniques, we demonstrate the fully printed ultraviolet (UV) solarblind photodetector by printing n-type $\mathrm{Ga}_{2} \mathrm{O}_{3}$ film over p-type $\mathrm{Si}$, the $p-n v d W$ heterojunctions property current rectification features with rapid photoresponse times and good sensibility for UV resource, which provides the performance of detection attributed to the solar-blind with stable and susceptible performances. The demonstrated liquid metal print framework reveals convenient and effective pathways for the preparation of 2D semiconductor photodetector that are vast area, cheap, and appropriate for mass production. Moreover, lower preparation temperature makes it possible for the printing process to be used on highly flexible polymer substrates such as polyimide in the future, which renders the possibility for an extensive spectrum of applications in next-generation of photodetection and optoelectronic instruments.

\section{RESULTS AND DISCUSSION}

\section{Liquid metal-based 2D semiconductors print}

Our printing process relies on the effective transfer and adhesion of oxide thin layers on metal surface. As shown in Fig. 1, the preparation process is divided into two steps: melting the metal and scraping off the parent metal of liquid metal. The oxide scale of liquid metals ( $\mathrm{Ga}, \mathrm{In}$, and $\mathrm{Sn}$ ) is atomic thin and has a weak binding force with the parent metal. It could be readily transferred and adhered to the required substrate by van der Waals force. Residual small metal droplets are removed by a solvent-assisted mechanical and chemical cleaning. Van der Waals force ensures that the oxide film adheres firmly to the substrate surface. After the completion of the whole process, large and continuous twodimensional semiconductor (metal oxide) thin films with a transverse scale of more than several centimeters can be obtained (details in "Experimental" section).

\section{Characterizations of $2 \mathrm{D}$ semiconductors $\mathrm{Ga}_{2} \mathrm{O}_{3} / \mathrm{ln}_{2} \mathrm{O}_{3} / \mathrm{SnO}$}

In order to select suitable 2D semiconductors films for optoelectronic devices, we measured the morphology and structural characterization of the printed $2 \mathrm{D} \mathrm{Ga}_{2} \mathrm{O}_{3}, \ln _{2} \mathrm{O}_{3}$, and $\mathrm{SnO}$ films on a $\mathrm{SiO}_{2} / \mathrm{Si}$ substrate, as shown in Fig. 2. The optical image of the semiconductors films is shown in the left part of Fig. 2, which indicates all films revealed lateral dimensions of several millimeters to near centimeters. The morphology of the surface and thickness of the printed films were surveyed through atomic force microscopy (AFM). Owing to the restricted scanning region size of AFM, a sole tiny part of the super gross semiconductor film is shown in the center of Fig. 2, which confirms the successful transfer and printing of the semiconductor layer. For the prined 2D Ga $\mathrm{O}_{3}$ films, the regular step height between the substrate and the $\mathrm{Ga}_{2} \mathrm{O}_{3}$ film is about $4.1 \mathrm{~nm}$, which is slightly thicker than the previously published sheet separated by liquid metal printing technology. Local metallic inclusions only occasionally appear at the edge of the large film. Each type of the 2D films prepared by this process has a different thickness: $4.1 \mathrm{~nm}$ for $\mathrm{Ga}_{2} \mathrm{O}_{3}, 3.2 \mathrm{~nm}$ for $\ln _{2} \mathrm{O}_{3}$, and $4.4 \mathrm{~nm}$ for $\mathrm{SnO}$. It has been proven by experiments that the printing technology can reproduce the formation of uniform centimeter-scale semiconductor films on different substrates (Supplementary Fig. S1). Relatively speaking, the quality of printed semiconductor film on $\mathrm{SiO}_{2} / \mathrm{Si}$ surface is optimal, so the subsequent characterization and device preparation are based on the $2 \mathrm{D}$ film printed on $\mathrm{SiO}_{2} / \mathrm{Si}$ surface.

High-resolution transmission electron microscopy known as (HRTEM) was utilized for illuminating the crystal configuration as well as structural properties attributed to the printed films. The right side of Fig. 2 shows the TEM image of the printed 2D semiconductor, the inset is a pattern of the selected area electron diffraction (SAED) of the chosen studied region. In Fig. 2a, it can be observed that the lattice spacing is $0.46 \mathrm{~nm}$, according to the $\mathrm{d}$-spacing value of the (201) plane of $\mathrm{Ga}_{2} \mathrm{O}_{3}$. From the HRTEM illustration and SAED pattern of $\ln _{2} \mathrm{O}_{3}$ in Fig. $2 \mathrm{~b}$, we can see that there exist two latticed d-spacing in the film. The $d$-spacing of $0.25 \mathrm{~nm}$ conforms to the (400) plane, whilst the other $0.28 \mathrm{~nm}$ $\mathrm{d}$-spacing is attributed to the (222) face of $\ln _{2} \mathrm{O}_{3}$. For $\mathrm{SnO}$, the $\mathrm{d}$-spacing of $0.26 \mathrm{~nm}$ conforms to the (110) plane of SnO (Fig. 2c). We also analyzed the X-ray photoelectron spectroscopy (XPS) and $X$-ray diffraction (XRD) of various oxide films to check the purity of the printed semiconductor films. XPS results show that there are only pure $\mathrm{Ga}_{2} \mathrm{O}_{3}, \ln _{2} \mathrm{O}_{3}$, and $\mathrm{SnO}$ in the $2 \mathrm{D}$ oxide films, but no metal elements and/or other oxides (see Supplementary Figs. S2 and S3 for detailed analysis). XRD results show that all the 2D oxide films have a good lattice structure, which matches well with the peak position of the standard spectrum (see Supplementary Fig. S4 for detailed analysis). The attained XPS data and the other characterization techniques aforementioned above provide the outcome that all of our printed 2D semiconductor materials have

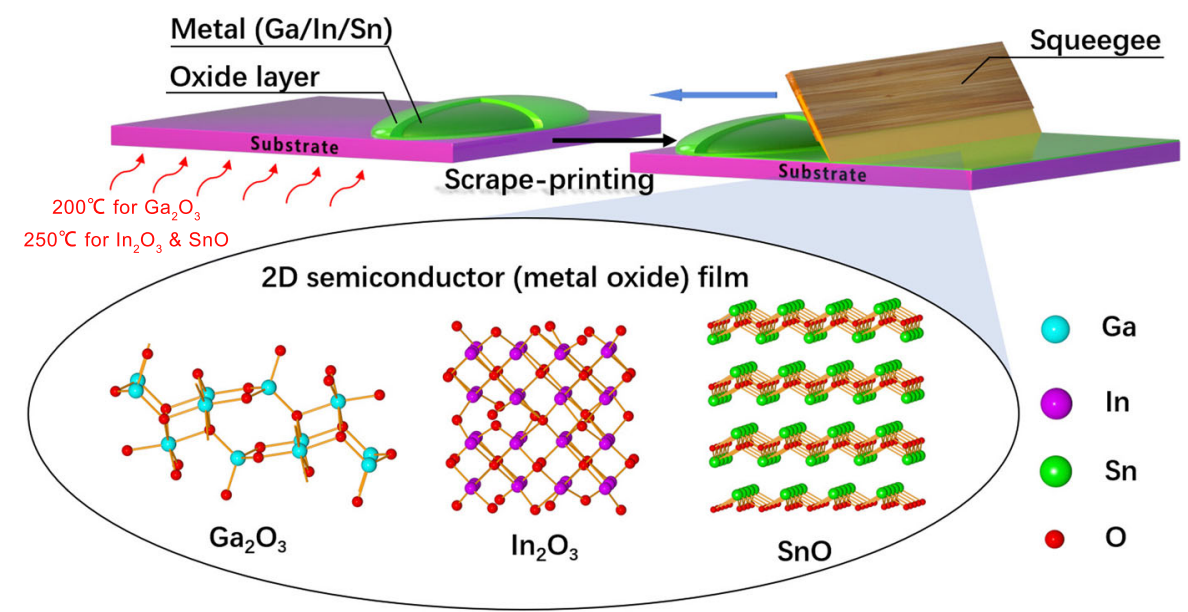

Fig. 1 Schematic of the 2D semiconductors printing process. Liquid metal can form atomic thin-layer metal oxides under atmospheric conditions. When the liquid metal was scraped amongst the surface of the silica layer with the "squeegee", the liquid parent metal is cleared off, however, the layer of oxide adheres to surface of the substrate to achieve a large-scale thin layer of the semiconductor. 
(a)

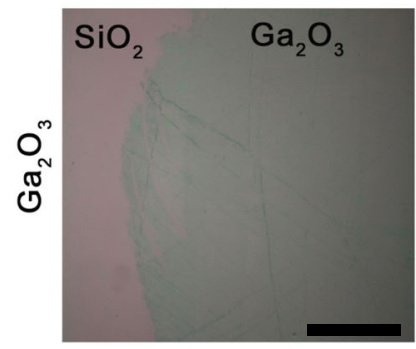

(b)

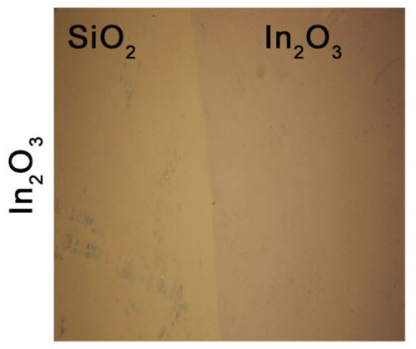

(c)

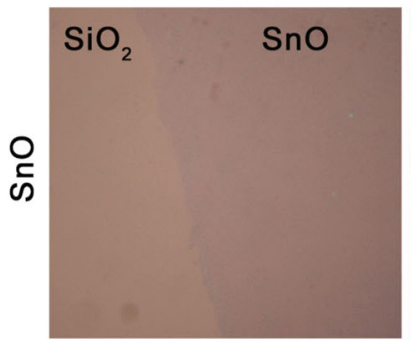

(d)

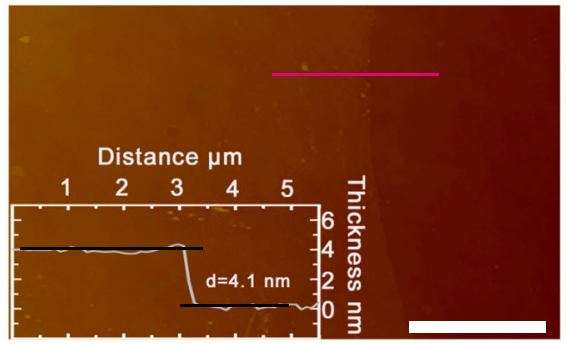

(e)

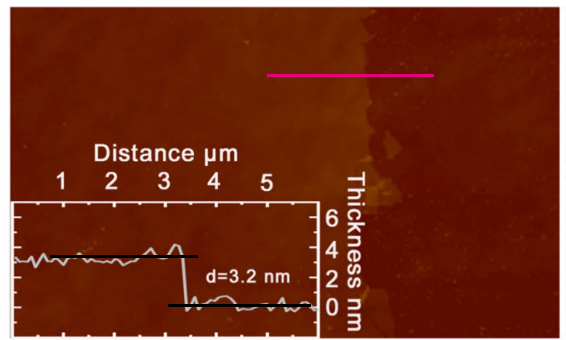

(f)

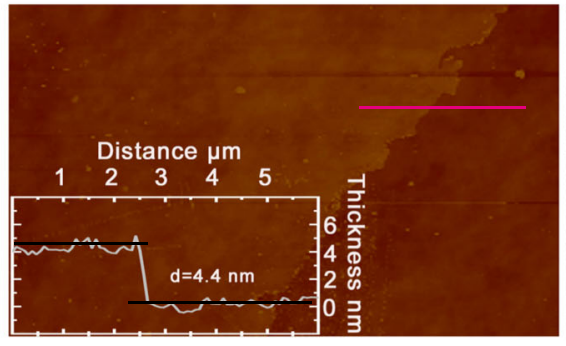

(g)

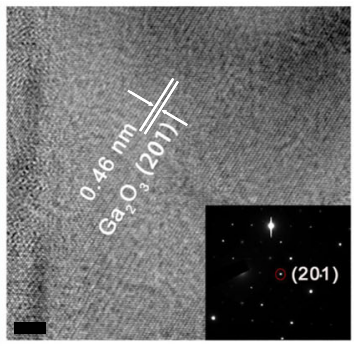

(h)

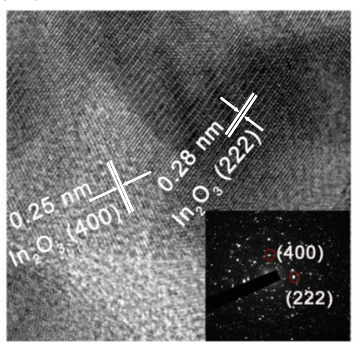

(i)

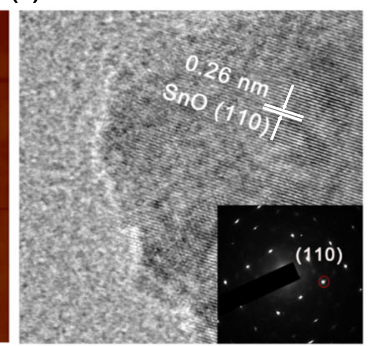

Fig. 2 Morphological and crystalline characterizations of the print 2D semiconductors. a-c optical images exhibit homogeneous films featuring lateral dimensions spanning multiple centimeters (scale bar, $0.5 \mathrm{~mm}$ ). $\mathbf{d}$-f AFM illustrations, with thickness profile (inset) specified at the red line as illustrated (scale bar, $5 \mu \mathrm{m}$ ). $\mathbf{g}$-i TEM characterization of the print semiconductors, including HRTEM images (scale bar, $0.5 \mathrm{~nm}$ ) and SAED pattern of the corresponding region (bottom inset).

good consistency and can be used for further characterization of electrical and photoelectric properties.

\section{Electrical and optical absorption characterization of printed 2D semiconductor material}

Due to the difference between 2D films prepared by printing and CVD, which may have some influence on the electronic and optical characteristics. First, we need to further explore the optical absorption characteristics of three 2D oxide materials prepared by printing method. The measured optical absorption results of $\mathrm{Ga}_{2} \mathrm{O}_{3}, \mathrm{In}_{2} \mathrm{O}_{3}$, and $\mathrm{SnO}$ films are shown in Fig. 3a. They revealed that the $\mathrm{Ga}_{2} \mathrm{O}_{3}$ film demonstrates potent absorption in the spectral area less than $250 \mathrm{~nm}$, and is approximately transparent in the spectral scope of $260-800 \mathrm{~nm}$, which indicates that the film has significant absorption in the ultraviolet area, particularly in the solar-blind area, it is an excellent material for fabricating UV detectors. The $\ln _{2} \mathrm{O}_{3}$ thin film has strong absorption ability to the ultraviolet light less than $400 \mathrm{~nm}$, but it also owns certain absorption ability to the violet light of $400-455 \mathrm{~nm}$ and the blue light of $455-492 \mathrm{~nm}$. The optical absorption band of SnO film have extended to the ultraviolet radiation $B$ region, in addition, the film exhibits a weak absorption in the solar-blind region. The ideal solar-blind UV photodetectors request that the devices have no response to the light with wavelength above $280 \mathrm{~nm}^{24}$. Therefore, for the construction of photodetector devices, the optical properties of $\mathrm{Ga}_{2} \mathrm{O}_{3}$ films are significantly better than those of $\ln _{2} \mathrm{O}_{3}$ and $\mathrm{SnO}$.
$\mathrm{Ga}_{2} \mathrm{O}_{3}$ is a direct bandgap semiconductor material ${ }^{25}$, so we evaluate the bandgap of the $\mathrm{Ga}_{2} \mathrm{O}_{3}$ films based on the spectrum of absorbance related to the $\mathrm{Ga}_{2} \mathrm{O}_{3}$ thin film. The corresponding bandgap energy $\left(E_{\mathrm{g}}\right)$ can be estimated by Tauc's analysis based on the equation.

$(a h v)^{2}=C \cdot\left(h v-E_{g}\right)$

In this equation, $h$ represents the Planck constant, $a$ stands for the linear coefficient of absorption, $v$ states the photon frequency, and $C$ is the constant. As exhibited in the illustration of Fig. $3 \mathrm{~b}$, via fitting the linear region between $(a h v)^{2}$ and the photon energy $h v$ axis, the bandgap of printed $\mathrm{Ga}_{2} \mathrm{O}_{3}$ is evaluated about $\approx 4.8 \mathrm{eV}$, which is in good agreement with the indirect transition of double-layer $\mathrm{Ga}_{2} \mathrm{O}_{3}$, which further proves the uniformity of the film. Figure $3 c$ shows a plot of $(a h v)^{2} v s$. $h v$ based on UV-vis absorption spectra of printed $2 \mathrm{D} \ln _{2} \mathrm{O}_{3}$. The Tauc plots diagram achieved by the analysis of UV-vis shows that the bandgap of $2 \mathrm{D} \ln _{2} \mathrm{O}_{3}$ is $\sim 3.1 \mathrm{eV}$, indicating that the film has a nearly inherent behavior. Similarly, the direct $E_{\mathrm{g}}$ for the printed SnO film was evaluated about $\sim 3.7 \mathrm{eV}$, near the already achieved outcome $E_{\mathrm{g}}$ for tetragonal SnO $(\sim 3.7 \mathrm{eV})^{26}$. The $(a h v)^{1 / 2} \mathrm{vs}$. $h v$ plot shows the existence of an indirect bandgap of $\sim 2.2 \mathrm{eV}$ (Fig. S5). A first-principle calculation suggests that the indirect bandgap is about $1.6 \mathrm{eV}$ smaller than the direct bandgap ${ }^{27}$, which is approximate to our current experimental values. For such printed $\mathrm{SnO}$, the value of indirect bandgap is a little larger than most of the general SnO. We speculate that the quality of the film (such as crystallite size, number of structural defects, chemical 
(a)

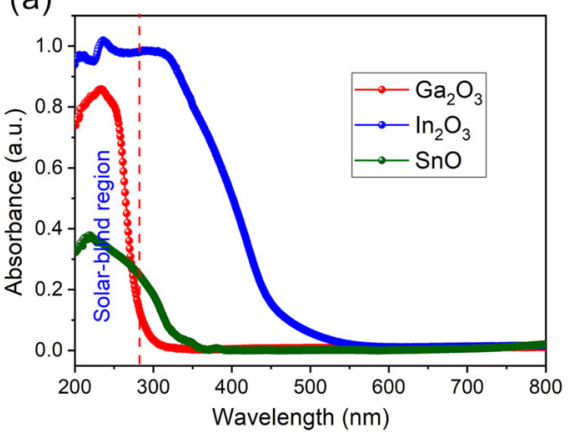

(c)

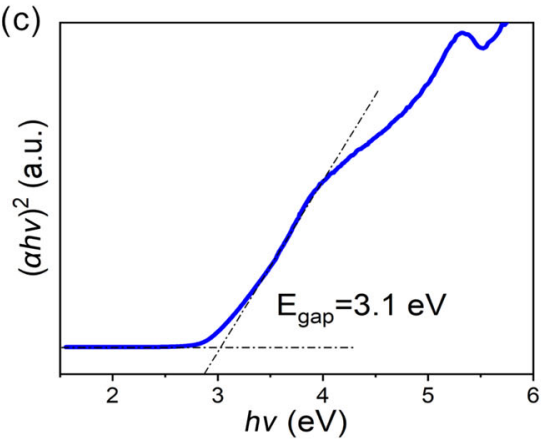

(b)
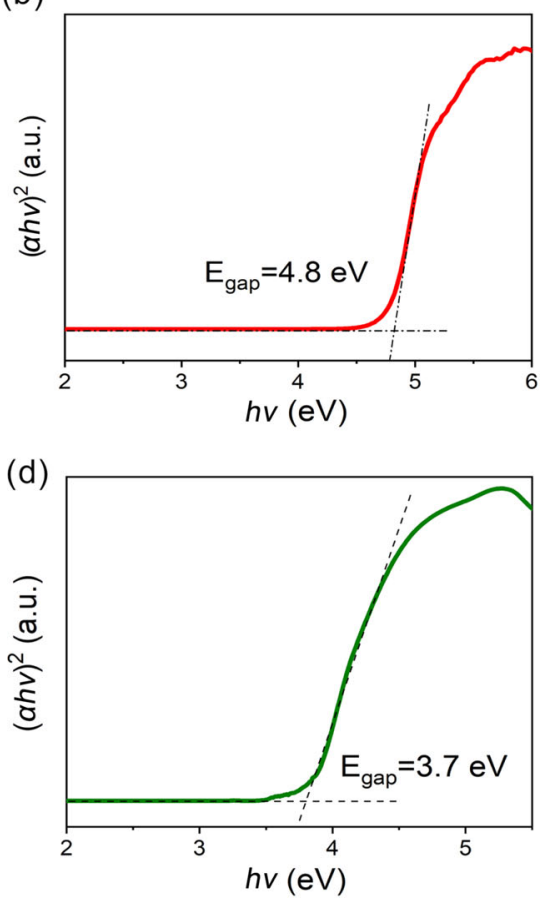

Fig. 3 The material properties and electronic band characterizations of printed 2D semiconductor. a The spectrum of the absorbance related to the printed $\mathrm{Ga}_{2} \mathrm{O}_{3}, \ln _{2} \mathrm{O}_{3}$, and $\mathrm{SnO}$ films. Tauc plot utilized in order to specify the electronic band gap for $\mathbf{b} \mathrm{Ga}_{2} \mathrm{O}_{3}, \mathbf{c} \ln \mathrm{O}_{3}$ and $\mathbf{d} \mathrm{SnO}$ with a clarified electronic band plot.

(a)

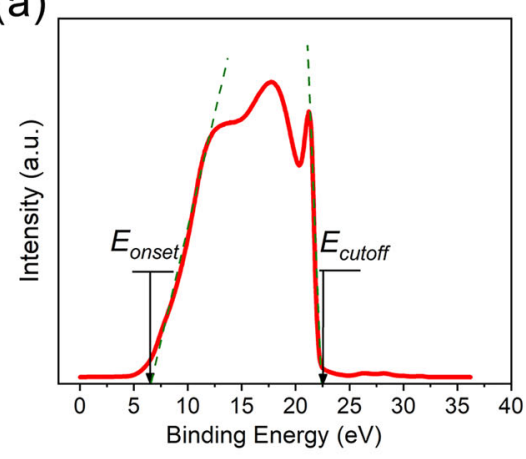

(b)

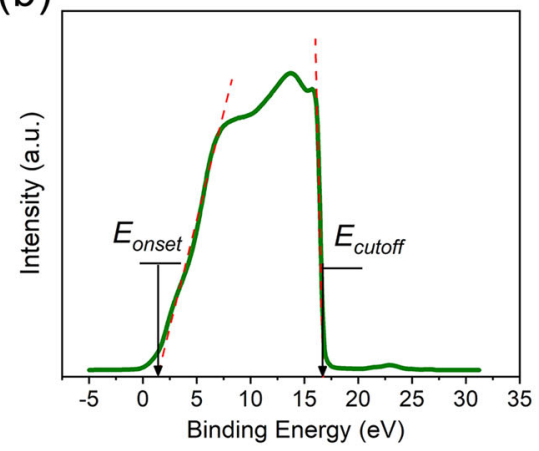

(c)

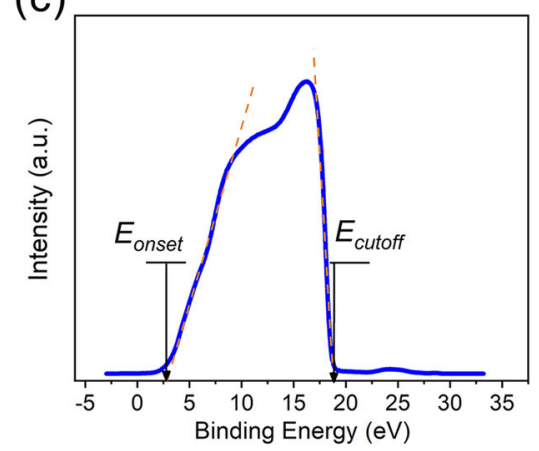

Fig. 4 The electrical properties of 2D semoconductor films. The evaluated UPS spectrum obtained from the printed a $2 \mathrm{D}-\mathrm{Ga}_{2} \mathrm{O}_{3}, \mathbf{b} \mathrm{In}_{2} \mathrm{O}_{3}$, and c SnO to identify their electron affinity value.

composition, etc, ${ }^{28,29}$ ) has a strong influence on the optical properties near the absorption edge.

In semiconductor electronic devices, the carriers are injected into the semiconductor from the electrical contact, and the devices utilize the fine control of the flow of the carrier. In theory, the work function represents the minimum energy required for the electron to escape from the material to the free space, and the electron affinity is the energy released when the electron falls from the free space to the bottom of the semiconductor conduction band. These parameters can provide important theoretical basis for exploring the contact properties between metal and 2D semiconductor, and the contact properties determine the performance of the device. Therefore, further research on the intrinsic electrical characteristics of 2D semiconductor is very important for the performance of $2 D$ electronic and optoelectronic devices.
Ultraviolet photoelectron spectroscopy (UPS) is a common method to characterize the electrical properties of the 2D semiconductor films, it was carried out in an ultra-high vacuum system supplied within the light resource of specs microwave ultraviolet ( $\mathrm{Hel}=21.2 \mathrm{eV}$; UV spot diameter is around $1 \mathrm{~mm}$ ). The UPS spectrum of the printed 2D semiconductor is shown in Fig. 4, which presents the cutoff region and the edge region of the valence band. By calculation, the conforming maximum value of valence band (VBM) value of $\mathrm{Ga}_{2} \mathrm{O}_{3}$ is $5.21 \mathrm{eV}$, while the electron affinity of printed $\mathrm{Ga}_{2} \mathrm{O}_{3}$ is $3.5 \mathrm{eV}$. Similarly, $\ln _{2} \mathrm{O}_{3}$ thin films exhibit $\mathrm{VBM}=6.03 \mathrm{eV}$, and the VBM energy of $\mathrm{SnO}$ is calculated to be $5.23 \mathrm{eV}$. The electron affinity of $\ln _{2} \mathrm{O}_{3}$ and $\mathrm{SnO}$ are calculated as 2.9 and $3.8 \mathrm{eV}$, respectively. (See Supporting material for detailed calculation process) These results agree with the theoretical very well, indicating that the printed $\mathrm{Ga}_{2} \mathrm{O}_{3}, \ln _{2} \mathrm{O}_{3}$, and $\mathrm{SnO}$ films have good electrical properties. Considering the optical absorption 
(a)
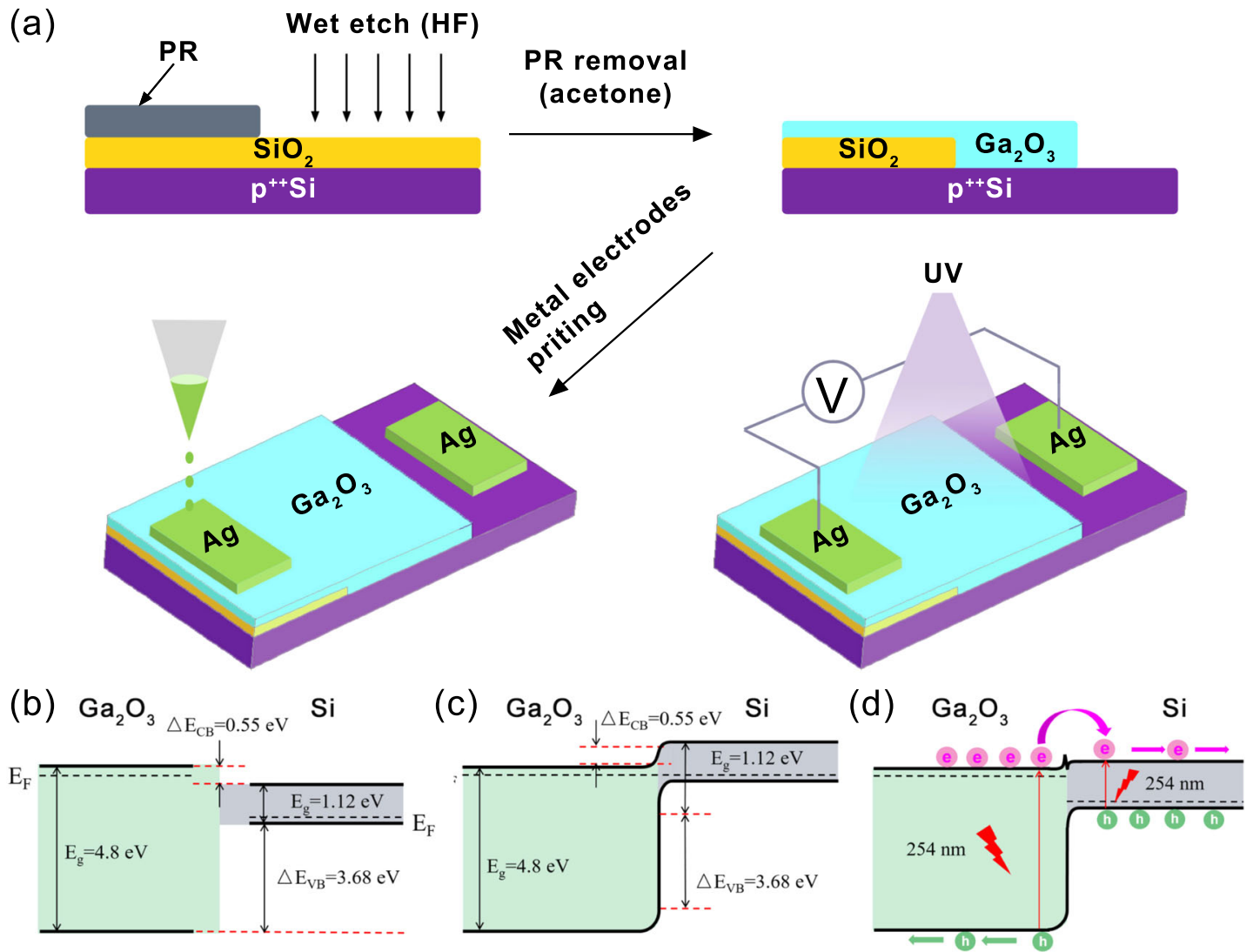

Fig. 5 Schematic image and energy band diagrams of the fully printed $\mathrm{Ga}_{2} \mathrm{O}_{3} / \mathrm{Si}$ heterojunction photodetector. a Fabrication process of the photodetector. Band diagrams of $n$-type $\mathrm{Ga}_{2} \mathrm{O}_{3}$ and $\mathrm{p}^{++} \mathrm{Si}$ heterostructure indicating $\mathbf{b}$ pre-junction creation, $\mathbf{c}$ post junction creation, and d under $254 \mathrm{~nm}$ illumination.

characteristics, band gap, VBM and electron affinity of the material, the printed $\mathrm{Ga}_{2} \mathrm{O}_{3}$ film is very suitable for the preparation of solar-blind UV photodetector. Therefore, we constructed and explored the photoelectric detector based on $\mathrm{Ga}_{2} \mathrm{O}_{3}$.

\section{Fully printed $\mathrm{Ga}_{2} \mathrm{O}_{3} / \mathrm{Si}$ heterojunction UV solar-blind photodetector}

Over the recent decades, photodetectors working within the ultraviolet (UV) solar-blind zone $(220-280 \mathrm{~nm})$ have attracted extensive attention in military and civil fields. In the present research, we fabricated a good responsivity fully printed solarblind UV photodetector founded on $\mathrm{Ga}_{2} \mathrm{O}_{3} / \mathrm{Si}$ p-n heterojunction via printing $n$-type $\mathrm{Ga}_{2} \mathrm{O}_{3}$ on p-type $\mathrm{Si}$. The electrical and optical features of the created $p-n$ heterojunction photodetector were investigated systematically, indicating the great potential of fully printed $\mathrm{Ga}_{2} \mathrm{O}_{3}$-based (opto) electronic devices.

The manufacturing process of the fully printed UV solar blind detector was depicted in Fig. 5a. The cleaned $\mathrm{SiO}_{2} / \mathrm{p}^{++} \mathrm{Si}(300 \mathrm{~nm} /$ $500 \mu \mathrm{m})$ substrate was relatively coated with photoresist and then immersed in the etchant buffer oxide (6:1 diluted $H F, B O E, j . t$. baker) for $5 \mathrm{~min}$. The subjected $\mathrm{SiO}_{2}$ was etched wetly to disclose potential $\mathrm{p}^{++} \mathrm{Si}$, and the etching quality was verified by measuring the resistance of the sheet by applying a four-probe connected to the source surface (Keithley 2400). $\mathrm{Ga}_{2} \mathrm{O}_{3}$ film was printed on patterned $\mathrm{SiO}_{2} / \mathrm{p}^{++} \mathrm{Si}$. As demonstrated in Fig. $5 \mathrm{a}$, one end of the deposited $\mathrm{Ga}_{2} \mathrm{O}_{3}$ creates a $\mathrm{p}$-n junction with $\mathrm{p}^{++}$Si within van der Waals effect, and the other end is completely isolated by $\mathrm{SiO}_{2}$ and $\mathrm{Si}$. Finally, the fabrication of $\mathrm{Ga}_{2} \mathrm{O}_{3} / \mathrm{Si}$ heterojunction photodetectors is completed by printing silver electrodes.

To attain a deep understanding of the pivoting role of the $\mathrm{Ga}_{2} \mathrm{O}_{3} / \mathrm{Si}$ heterojunction in ameliorating the optoelectronic performance and display the operation mechanism in the studied photodetector, the diagrams of energy band related to the $\mathrm{Ga}_{2} \mathrm{O}_{3} / \mathrm{Si}$ heterojunction with dark circumstance and UV illumination are both indicated in Fig. 5b-d. Because the gap width of $\mathrm{Ga}_{2} \mathrm{O}_{3}$ is $4.8 \mathrm{eV}$, the carrier concentration of $\mathrm{Ga}_{2} \mathrm{O}_{3}$ film is remarkably less than that of $p-\mathrm{Si}$, a $\mathrm{p}-\mathrm{n}$ junction is created. We used the Anderson model to explain the band diagram of $\mathrm{Ga}_{2} \mathrm{O}_{3} / \mathrm{p}$-Si heterojunction ${ }^{30}$. The values of the conduction band offset $\left(\Delta E_{\mathrm{CB}}\right)$ and valance band offset $\left(\Delta E_{\mathrm{VB}}\right)$ were determined using Anderson's rule (Fig. 5b-d). According to the difference of electron affinity between $\mathrm{Ga}_{2} \mathrm{O}_{3}(3.5 \mathrm{eV})$ and $\mathrm{Si}(4.05 \mathrm{eV}), \Delta E_{\mathrm{CB}}$ was estimated to be $0.55 \mathrm{eV}$. Based on the band gaps of 4.8 and $1.12 \mathrm{eV}$ for $\mathrm{Ga}_{2} \mathrm{O}_{3}$ and $\mathrm{Si}$, the $\Delta E_{\mathrm{VB}}$ value was calculated to be $3.68 \mathrm{eV}$. Considering all the values, the band diagrams of $\mathrm{Ga}_{2} \mathrm{O}_{3}$ and $\mathrm{Si}$ before and after junction formation are shown in Fig. $5 \mathrm{a}, \mathrm{b}$, respectively. When $\mathrm{Ga}_{2} \mathrm{O}_{3}$ is applied with a positive voltage, the depletion layer composed of $\mathrm{Ga}_{2} \mathrm{O}_{3}$ layer will expand. Since the impedance of $\mathrm{Ga}_{2} \mathrm{O}_{3}$ is far greater than that of $\mathrm{Si}$, almost all voltages are applied to $\mathrm{Ga}_{2} \mathrm{O}_{3}$. As displayed in Fig. $5 c$, when $\mathrm{Ga}_{2} \mathrm{O}_{3} / \mathrm{p}$-Si heterojunction is irradiated by $254 \mathrm{~nm}$ ultraviolet light, its photon energy is sufficient to excite the carrier of $\mathrm{Ga}_{2} \mathrm{O}_{3}$, the carrier generated by light excitation gets high energy under the acceleration of a large electric field in the junction region, and then collides with other atoms in the ionization junction region to generate carriers, and the avalanche multiplication effect is obtained. The electrons can be easily transferred into $\mathrm{p}$-Si to obtain high photocurrent and responsivity. Therefore, the photocurrent of $\mathrm{Ga}_{2} \mathrm{O}_{3} / \mathrm{p}$-Si heterojunction increases exponentially with the applied voltage after being irradiated by $254 \mathrm{~nm}$ UV light. It is understood that the instrument has only the following ideal response wavelength of $254 \mathrm{~nm}$. However, the ultraviolet energy at $365 \mathrm{~nm}$ is not sufficient to excite the electrons in the valence band of $\mathrm{Ga}_{2} \mathrm{O}_{3}$, and the above gain phenomenon will not occur. Therefore, the heterojunction photodetectors have solar-blind ultraviolet characteristics. When a negative 
(a)

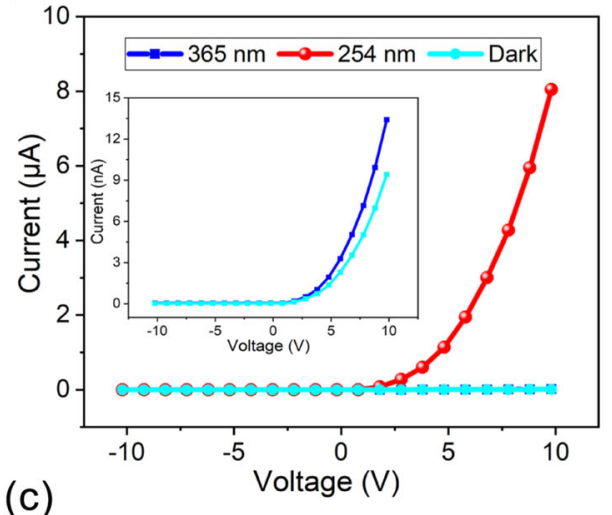

(c)

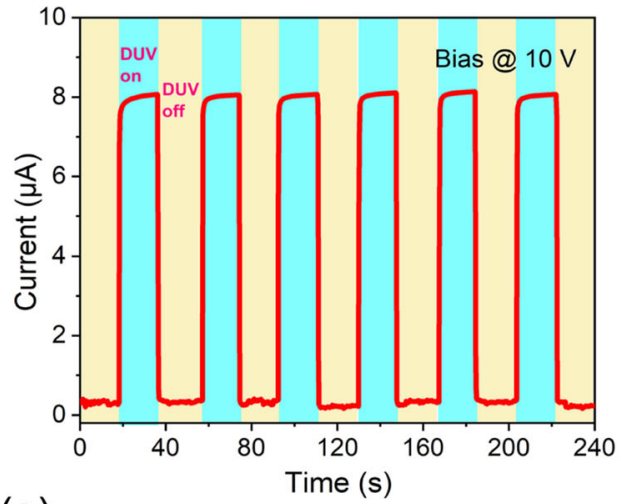

(e)

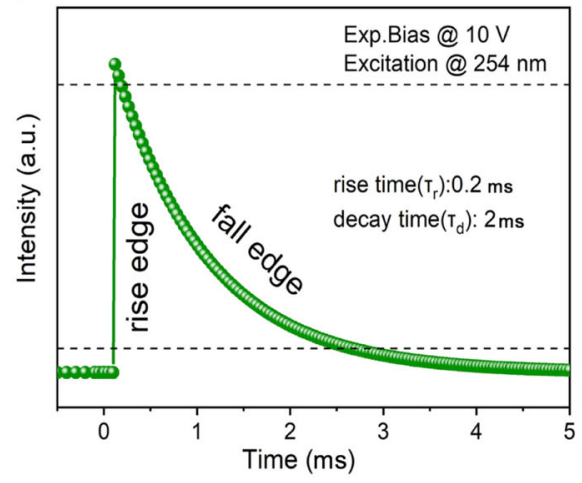

(b)
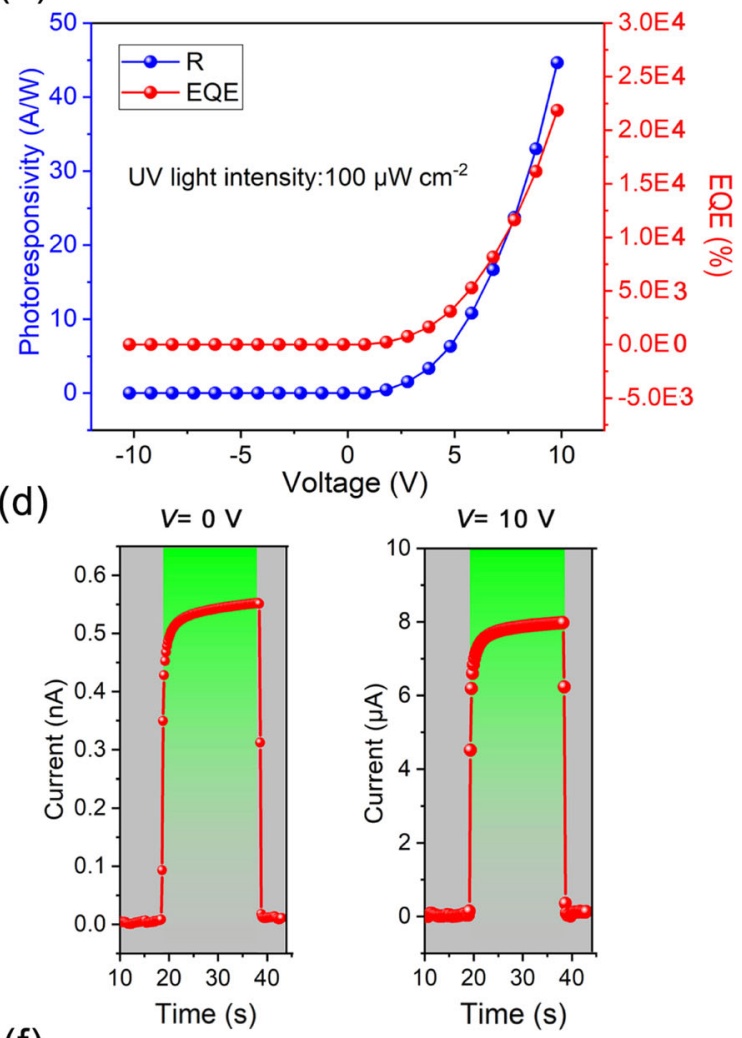

(f)

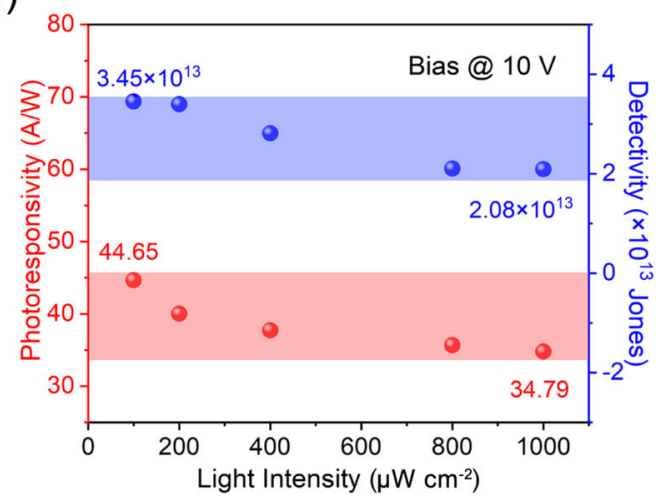

Fig. 6 Characterization of the fully printed UV photodetector founded on $\mathrm{Ga}_{2} \mathrm{O}_{3} / \mathrm{Si}$ heterojunction. a The linear-scale I-V features in the dark and under $254 \mathrm{~nm}$ and $365 \mathrm{~nm}$ UV light resources of $100 \mu \mathrm{W} \mathrm{cm}{ }^{-2}$. b The $254 \mathrm{~nm}$ UV light responsibility and the efficiency of external quantum at various implemented voltages. c Reproducible on/off switching of photodetector cell under $254 \mathrm{~nm}$ light at $10 \mathrm{~V}$. d Time-resolved photocurrent assessments under laser resources. The green-shaded areas exhibit laser illumination for $20 \mathrm{~s}$. e $\mathrm{Time}$ response of $\mathrm{Ga}_{2} \mathrm{O}_{3} / \mathrm{Si}$ photodetector. $\mathbf{f}$ Photoresponsivity and photodetectivity as a function of the great intensities at $10 \mathrm{~V}$.

voltage is exerted to $\mathrm{Ga}_{2} \mathrm{O}_{3}$, the depletion layer is approached, since the intercepted barrier electrons and holes cannot be transported into p-Si.

We thoroughly investigate the electrical and photoelectric performance of the $\mathrm{Ga}_{2} \mathrm{O}_{3} / \mathrm{Si}$ heterojunction device. Figure $6 \mathrm{a}$ indicates the current-voltage $(I-V)$ properties of the photodetector instrument impacted by various circumstances, the voltage is applied between the two Ag electrodes. A $254 \mathrm{~nm}$ low voltage lamp was utilized as an ultraviolet light source. It can be seen from the results that the reverse current density is tinier than the applied forward one, confirming the creation of junction hindrance. (The Ag electrode on $\mathrm{Ga}_{2} \mathrm{O}_{3}$ is connected to $0 \mathrm{~V}$, and the voltage applied to the Ag electrode on $\mathrm{p}$-Si is higher than $0 \mathrm{~V}$, which is called forward voltage.) Around the bias of $10 \mathrm{~V}$, the photodetector shows a dark current as low as $9.41 \times 10^{-3} \mu \mathrm{A}$, whilst the corresponding photocurrent is around $8.1 \mu \mathrm{A}$, which is about $10^{3}$ times higher than the dark current. The current of low dark and high ratio of $I_{\text {photo }} / I_{\text {dark }}$ show that the detector has a notable ratio of signal-to-noise. The photocurrent at $365 \mathrm{~nm}$ is approximately equal to the dark current, indicating that $\mathrm{Ga}_{2} \mathrm{O}_{3} / \mathrm{Si}$ heterojunction has no response to $365 \mathrm{~nm}$ wavelength (UV-A) (inset of Fig. 6a). The response of the device to the wavelength of $254 \mathrm{~nm}$ (UV-C) shows that the $\mathrm{Ga}_{2} \mathrm{O}_{3} / \mathrm{Si}$ heterojunction is solar blind. In particular, because of the $\mathrm{p}-\mathrm{n}$ junction structure used in our optoelectronic devices, it can display the function of UV photodiode and photodetector at the same time. So it has significant advantages in complex photoelectric systems such as multi-functional optoelectronic applications.

For the aim of a quantitative assessment of the behavior of photodetectors, the peak responsivity $(\mathrm{R})$ at applied bias voltage is 
studied in Fig. $6 \mathrm{~b}$, and the light intensity is $100 \mu \mathrm{W} \mathrm{cm}-2$ Responsivity is described through the Eq. (2):

$R=\frac{I_{\lambda}-I_{d}}{P_{\lambda} S}$

In the aforementioned equation, $I_{\lambda}$ states the photocurrent, $I_{\mathrm{d}}$ represents the dark current, $P_{\lambda}$ states the light intensity and $S$ is the area of efficient illumination $\left(0.18 \mathrm{~mm}^{2}\right)$. As illustrated in Fig. $6 \mathrm{~b}$, the responsivity of the peak related to the photodetectors improves linearly with the increase of implemented bias voltage. The maximum responsivity can reach $44.6 \mathrm{~A} \mathrm{~W}^{-1}$ at $10 \mathrm{~V}$ voltage and $100 \mu \mathrm{W} \mathrm{cm} \mathrm{cm}^{-2}$ light intensity. The results show that the photodetector has good spectral response to the solar-blind light. The external quantum efficiency (EQE) is the other essential performance index of photodetectors, it could be explained by the Eq. $(3)^{31}$ :

$\operatorname{EQE}(\eta)=\frac{h c R_{\lambda}}{q \lambda}$

where $h$ represents the Planck constant, $c$ is the light speed, $q$ is the charge of an initial electron $\left(1.6 \times 10^{-19} \mathrm{C}\right), \lambda$ states the wavelength of incident ultraviolet light $(254 \mathrm{~nm})$, and $R_{\lambda}$ is the response to a specific ultraviolet wavelength. Figure $6 \mathrm{~b}$ also shows the change of EQE of photodetector with applied bias voltage under $254 \mathrm{~nm}$ illumination. For our device, the peak responsivity at $254 \mathrm{~nm}$ is around $44.6 \mathrm{~A} \mathrm{~W}^{-1}$, and the corresponding EQE value is as great as $2.2 \times 10^{4} \%$ (at $10 \mathrm{~V}$ bias), which indicates that the photodetector and resources of ultraviolet light are well-coupled and can be used for UV detection ${ }^{32}$. Alike to the trend of $R$, EQE enhances with the increase of implemented voltage under forward bias voltage, which indicates that the photodetector has a great gain ${ }^{33}$.

In evaluating photodetectors, response time is an important basic characteristic, especially in applications requiring a fast light response. The time-dependent photocurrent curve $(I-t)$ of photodetectors was appraised via periodically turning on and off the light switch. During the measurement, we repeatedly turn on and off the $254 \mathrm{~nm}, 100 \mu \mathrm{W} \mathrm{cm}{ }^{-2} \mathrm{UV}$ light source at $20 \mathrm{~s}$ interval. Figure $6 \mathrm{c}$ shows the transient reaction of the $\mathrm{Ga}_{2} \mathrm{O}_{3} / \mathrm{Si}$ photodetector. A time-dependent optical response was obtained at a forward bias voltage of $10 \mathrm{~V}$. The photocurrents time-resolved $(\mathrm{V}=0$ and $10 \mathrm{~V})$ of $20 \mathrm{~s}$ before and after laser irradiation were also measured to study the photodecay time $\left(\tau_{\text {decay }}\right)$ (Fig. $6 \mathrm{~d}$ ). As presented in Fig. $6 \mathrm{c}$ and $\mathrm{d}$, the current improves instantaneously from $\sim 0.6 \mathrm{nA}$ to $\sim 8.1 \mu \mathrm{A}$ under illumination, and rapidly decays to $\sim 0.8 \mathrm{nA}$ when the light source is turned off.

In addition, under $365 \mathrm{~nm}$ illumination, we hardly observe the photocurrent change (Supplementary Fig. S6), which is superior to other reported $\mathrm{Ga}_{2} \mathrm{O}_{3}$ photodetectors with certain response to $365 \mathrm{~nm}$ wavelength ${ }^{34-37}$. Theoretically, when there are deep level defects, the detector can absorb wavelengths longer than the bandgap energy. The detector has no obvious light response at $365 \mathrm{~nm}$, which proves the high quality of printing materials and the excellent combination between $\mathrm{Ga}_{2} \mathrm{O}_{3}$ and $\mathrm{Si}$.

The reaction speed is another critical criterion of photodetectors, which is about the effective extraction of photogenerated carriers. The time-resolved response of the instrument is further investigated using an additional femtosecond pulse laser as well as an oscilloscope at $266 \mathrm{~nm}$. The results are shown in Fig. 6e. The rise time $\left(\tau_{r}\right)$ and the falling time $\left(\tau_{f}\right)$ exerted to observe the sensitivity and response. For a more detailed study, the transient response curve is fitted by exponential relaxation equation as follows:

$I=I_{0}+A e^{-t / \tau}$

where $I_{0}$ shows the photocurrent in a stable state, $A$ represents a constant, $t$ stands for the time, and $\tau$ states the constant of relaxation time. $\tau_{\mathrm{r}}$ and $\tau_{\mathrm{f}}$ represent the increase and decrease edges of the time constants, respectively. As displayed in Fig. 6e, the photoresponse treatment could be well-fitted with $\tau_{r}$ of $0.2 \mathrm{~ms}$ and $\tau_{\mathrm{f}}$ of $2 \mathrm{~ms}$. The procedure of fast decay could be ascribed to band-to-band transition, whilst the reduced speed one is attributed to the transition included within the traps ${ }^{38}$.

The detectivity $\left(D^{*}\right)$, which implies the potential of detection the weak signals from a noisy ambient, is one of the most important features of a photodetector that explains the least number of detectable signals. Definitely, this benchmark is stated as follows ${ }^{39}$ :

$$
\mathrm{D}^{*}=\frac{R_{\lambda}}{\sqrt{2 q l_{d} / S}}
$$

Due to the repressed dark current and improved responsivity, considering that $R_{254}=44.6 \mathrm{~A} \mathrm{~W}^{-1}$ and $I_{\mathrm{d}}=4.6 \times 10^{-5} \mu \mathrm{A}$, the $D^{*}$ value of the $\mathrm{Ga}_{2} \mathrm{O}_{3} / \mathrm{Si}$ heterostructure photodetector could be measured to be $3.45 \times 10^{13} \mathrm{~cm} \mathrm{~Hz}^{1 / 2} \mathrm{~W}^{-1}$ (Jones) at the wavelength of $254 \mathrm{~nm}$, exhibiting a potent capability of the photodetector to ascertain the normalized signal-to-noise behavior. We further characterized the responsivity and detectivity by different light intensities (Fig. 6f). The fully printed $\mathrm{Ga}_{2} \mathrm{O}_{3} / \mathrm{Si}$ photodetector exhibited competitive photoresponsivity and photodetectivity.

Table 1 indicates a comparison of the $\mathrm{Ga}_{2} \mathrm{O}_{3}$ photodetector fabricated by our group, together with other works, the important parameters are given in the table. It could be observed from the comparison that the $\mathrm{Ga}_{2} \mathrm{O}_{3} / \mathrm{Si}$ detector constructed by us shows some encouraging and excellent performance. Some key parameters are better than the instruments founded on $\mathrm{Ga}_{2} \mathrm{O}_{3}{ }^{40,41}$, PEDOTs $/ \mathrm{Ga}_{2} \mathrm{O}_{3}{ }^{42}$, graphene $/ \mathrm{\beta}-\mathrm{Ga}_{2} \mathrm{O}_{3}{ }^{43,44}$, and some devices made of $\mathrm{AlGaN}^{45,46}, \mathrm{MgZnO}^{47,48}$, and $\mathrm{ZnO}^{49,50}$ et al. Although compared with the best performance photodetectors, there are still some differences in some parameters, but our work adopts the fully printing method based on liquid metal. Compared with other methods, it has great advantages in the rapid preparation of largearea semiconductor films, which is critical for the construction of large-scale and complex photoelectric systems. In addition, our process does not require a high-temperature process, which means that it is feasible to print semiconductor films on flexible polymer substrates such as PI. The liquid metal and the semiconductor films are heat-resistant, which means that this method can also be used in high-temperature manufacturing processes such as chip processing. This technology has the possibility to be extended to the application of flexible photoelectric system and high-temperature photoelectric detection. In summary, the partially great behavior, along with simple, facile fabrication and inexpensive represents the fully printed photodetector promising desirable potential expectancy for producing flexible high-speed optoelectronic systems. Moreover, our devices may further develop in the implementation of the hybrid circuit scheme based on low dimensional materials and should pave the way to develop print large-scale, low-cost, and desirable performance photoelectronic systems in the future.

Liquid metals have different potential functionalities. A pretty important value of this series of materials is that they can be adopted to print two-dimensional semiconductor materials with wide applications. In the present work, large-scale high-quality thin 2D semiconductor films have been demonstrated on different substrates using a scalable and facile printing method, through transferring the occurring oxide skin of liquid metal formed under certain conditions. Moveover, we have carried out a thorough interpretation and analysis on the electrical properties of printed 2D semiconductor films, providing key guidance for further development of functional liquid metal printed electronics.

In particular, we successfully exhibited the fully printed solarblind photodetector based on $\mathrm{Ga}_{2} \mathrm{O}_{3} / \mathrm{Si} \mathrm{p}-\mathrm{n}$ junction, which shows a pretty high responsivity and super detectivity for solarblind ultraviolet light detection. Such high efficiency, simple, large- 
Q. Li et al.

Table 1. Comparison of the most essential criteria of the photodetectors achieved in the current and previous investigations.

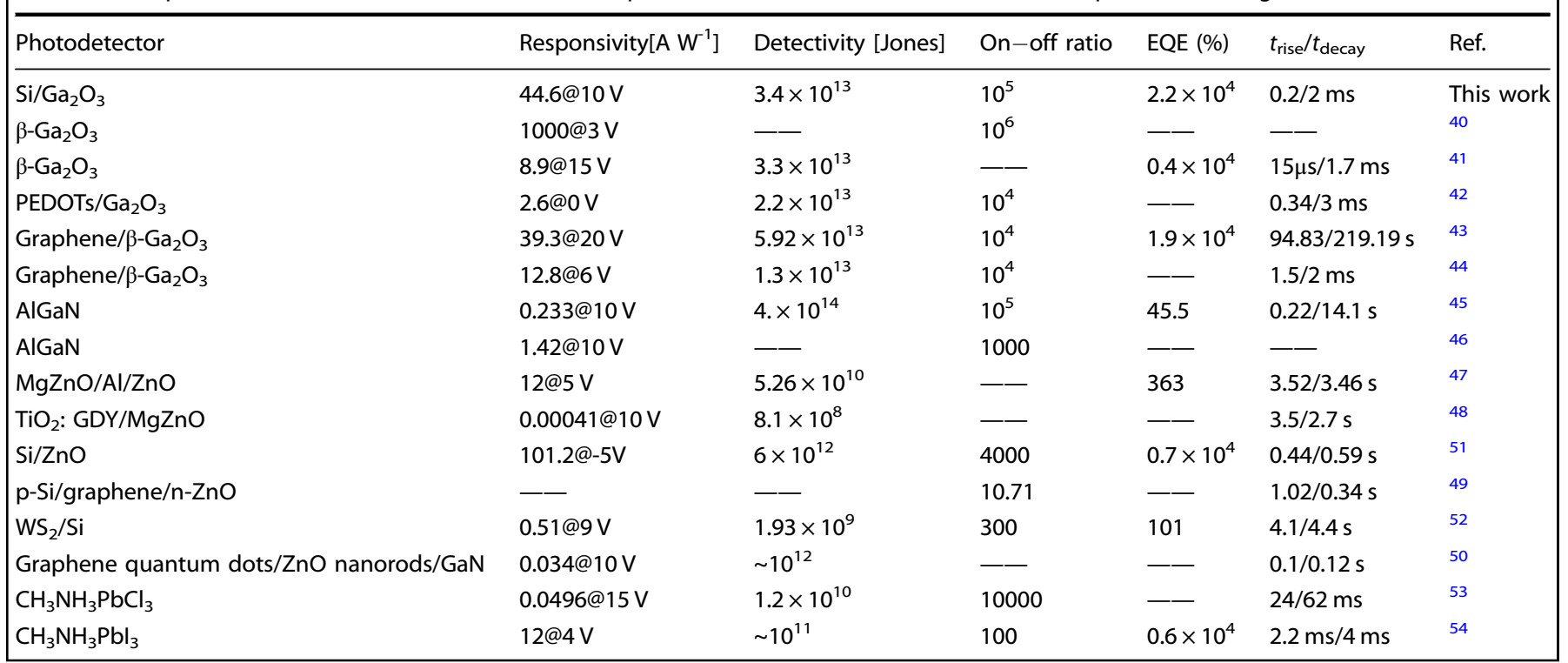

size, and inexpensive manufacturing process suggests a way with great commercial potential for advancing UV photodetectors with diverse engineering values. The advantages as offered may make the two-dimensional semiconductor thus produced as preferred material in printing various flexible optoelectronic devices, which provides a very potential paradigm for future electronics, sensors, and more functional devices.

\section{METHODS \\ Materials}

Gallium (Ga, 99.99\%), tin (Sn, 99.8\%) and indium (In, 99.98\%) were obtained from Roto Metals. Silver nanoparticle inks were obtained from Shanghai Mifang Electronic Technology Co., Ltd.

\section{Printing process of 2D semiconductor films}

$\mathrm{Ga}_{2} \mathrm{O}_{3}$ : A self-restricting atomically slim gallium oxide shell creates on the surface of gallium drops as they experienced exposure to atmospheric air. Gallium melts at $29.76^{\circ} \mathrm{C}$, a droplet of gallium collected utilizing a needle was located on a $\mathrm{SiO}_{2} / \mathrm{Si}$ substrate. The $\mathrm{SiO}_{2} / \mathrm{Si}$ substrate with gallium droplets on the surface is placed on a hotplate, the complete printing procedure was performed on the hotplate with temperature adjusted at $200^{\circ} \mathrm{C}$. The $2 \mathrm{D}$ oxide films altered dimensionally with the droplet diameter. At heating condition, a scraper is used to gently scrape the droplet from one end of the substrate to the other, the gallium oxide film could be transfer printed to the substrate. If additional force is utilized during the squeezing level, the oxide layer may be damaged. High-quality $\mathrm{Ga}_{2} \mathrm{O}_{3}$ films with a transverse dimension larger than several centimeters can be printed on the substrate effectively by this extrusion printing method.

$\mathrm{In}_{2} \mathrm{O}_{3}$ and $\mathrm{SnO}$ : First, the $\mathrm{SiO}_{2} / \mathrm{Si}$ substrates were all preheated to $250{ }^{\circ} \mathrm{C}$ to refrain from nucleation of the liquid metal upon contact. Secondly, indium metal with high purity was melted on the substrates provided at the same temperature. Thirdly, we use the same printing method to transfer the $2 \mathrm{D} \ln _{2} \mathrm{O}_{3}$ oxide films to the $\mathrm{SiO}_{2} / \mathrm{Si}$ substrate. The print of $2 \mathrm{D}$ $\mathrm{SnO}$ films comprises a similar three-step process.

\section{Mechanical and chemical cleaning process}

A facile mechanical ethanol cleaning approach was utilized to erase any liquid metal components remaining on the sample. First, take about $100 \mathrm{ml}$ of ethanol in a beaker, then heat the beaker on a heating plate to $100^{\circ} \mathrm{C}$. The substrate with printed $2 \mathrm{D}$ oxide film is then immersed in hot ethanol with tweezers. Metal residues are removed by wiping the substrate immersed in ethanol using a wiping tool (swab). There is a potent van der Waals adhesion amongst the oxide film and the bottom layer, and the oxide film still adheres to the silicon oxide surface during wiping proceeding. On the other hand, there is only a weak adhesion among the deposited oxide and the liquid metal and film, which can be easily erased to keep the 2D film clean and intact. Further, in order to completely and thoroughly remove the metal residue on the substrate, we use a chemical process to clean the samples. An lodine/triiodide $\left(\mathrm{I}^{-} / \mathrm{l}_{3}{ }^{-}\right)$solution $(100 \mathrm{mmol}$ $\mathrm{L}^{-1} \mathrm{Lil}$ and $5 \mathrm{mmol} \mathrm{L}^{-1} \mathrm{I}_{2}$ ) was prepared in ethanol and then placed on a hot plate to heat till $50^{\circ} \mathrm{C}$. The substrate printed with $2 \mathrm{D}$-semiconductor film was immersed in a heated $\mathrm{I}^{-} / \mathrm{I}_{3}{ }^{-}$solution for a period of time to completely remove metallic inclusions. Finally, the sample was cleaned in deionized water to remove the residual etchant. The above two cleaning processes can remove liquid metal particles conveniently and effectively.

\section{Characterization}

In order to determine the features of the 2D semiconductor thin film and the behaviors of the constructed instruments, various assessments were carried out. The AFM images were employed by a Bruker Dimension Icon with "Scanasyst-air" AFM tips. The high-resolution TEM images were taken utilizing JEOL 2100F TEM operating with $100 \mathrm{keV}$ electron beam energy. XRD was taken utilizing Bruker D8 micro-diffractometer supplied with a detector model Vantec 500 and $0.5 \mathrm{~mm}$ collimator. XPS analysis was conducted by Thermo Scientific K-alpha XPS spectrometer supplied with monochromatic $\mathrm{X}$-rays from an Al anode ( $h v=\sim 1486.6 \mathrm{eV})$. The optical bandgaps of the film were assessed by employing a UV-visible (UV-vis) absorbance spectrometer (Hitachi U3900 UV-vis spectrophotometer). The photoelectric performance of the photodetector was measured by an intensity tuned UV lamp $(254 \mathrm{~nm}$ and $365 \mathrm{~nm}$ ), monochromator, a program-controlled semiconductor determination system (Keithley 4200), a femtosecond pulsed laser as well as a digital oscilloscope (Tektronix TBS 1102), respectively.

\section{DATA AVAILABILITY}

The data that support the findings of this study are available from the corresponding author upon reasonable request.

Received: 19 November 2020; Accepted: 15 March 2021; Published online: 08 April 2021

\section{REFERENCES}

1. Forrest, S. R. The path to ubiquitous and low-cost organic electronic appliances on plastic. Nature 428, 911-918 (2004).

2. Novoselov, K. S. et al. Two-dimensional atomic crystals. PNAS 102, 10451-10453 (2005). 
3. Van der Zande, A. M. et al. Grains and grain boundaries in highly crystalline monolayer molybdenum disulphide. Nat. Mater. 12, 554-561 (2013).

4. Kang, K. et al. High-mobility three-atom-thick semiconducting films with waferscale homogeneity. Nature 520, 656-660 (2015).

5. Gao, M. \& Gui, L. Development of a fast thermal response microfluidic system using liquid metal. J. Micromech. Microeng. 26, 075005 (2016).

6. Sheng, L., Teo, S. \& Liu, J. Liquid-metal-painted stretchable capacitor sensors for wearable healthcare electronics. J. Med. Biol. Eng. 36, 265-272 (2016).

7. Yu, Y., Zhang, J. \& Liu, J. Biomedical implementation of liquid metal ink as drawable ECG electrode and skin circuit. PLOS ONE 8, e58771 (2013).

8. Li, Q., Lin, J., Liu, T., Zheng, H. \& Liu, J. Printed flexible thin-film transistors based on different types of modified liquid metal with good mobility. Sci. China Inform. 62, 202403 (2019).

9. Zheng, Y., He, Z., Gao, Y. \& Liu, J. Direct desktop printed-circuits-on-paper flexible electronics. Sci. Rep. 3, 1786 (2013).

10. Rao, W. \& Liu, J. Injectable liquid alkali alloy based-tumor thermal ablation therapy. Minim. Invasiv. Ther. 18, 30-35 (2009).

11. Yi, L., Jin, C., Wang, L. \& Liu, J. Liquid-solid phase transition alloy as reversible and rapid molding bone cement. Biomaterials 35, 9789e9801 (2014).

12. Lin, J. et al. Printing of quasi-2D semiconducting $\beta-\mathrm{Ga}_{2} \mathrm{O}_{3}$ in constructing electronic devices via room-temperature liquid metal oxide skin. Phys. Status Solidi 13, 1900271 (2019).

13. Messalea, $\mathrm{K}$. et al. $\mathrm{Bi}_{2} \mathrm{O}_{3}$ monolayers from elemental liquid bismuth. Nanoscale 10, 15615-15623 (2018).

14. Daeneke, T. et al. Wafer-scale synthesis of semiconducting SnO monolayers from interfacial oxide layers of metallic liquid tin. ACS Nano 11, 10974-10983 (2017).

15. Atkin, P. et al. Evolution of $2 \mathrm{D}$ tin oxides on the surface of molten tin. Chem. Commun. 54, 2102-2105 (2018).

16. Datta, R. S. et al. Flexible two-dimensional indium tin oxide fabricated using a liquid metal printing technique. Nat. Electron. 3, 51-58 (2020).

17. Syed, N. et al. Printing two-dimensional gallium phosphate out of liquid metal. Nat. Commun. 9, 3618 (2018).

18. Syed, N. et al. Wafer-sized ultrathin gallium and indium nitride nanosheets through the ammonolysis of liquid metal derived oxides. J. Am. Chem. Soc. 141, 104-108 (2019).

19. Carey, B. J. et al. Wafer-scale two-dimensional semiconductors from printed oxide skin of liquid metals. Nat. Commun. 8, 14482 (2017).

20. Alsaif, M. Y. A. et al. Atomically thin $\mathrm{Ga}_{2} \mathrm{~S}_{3}$ from skin of liquid metals for electrical, optical, and sensing applications. ACS Appl. Nano Mater. 2, 4665-4672 (2019).

21. Zeng, M. et al. Molecular scaffold growth of two-dimensional, strong interlayerbonding-layered. Mater. CCS Chem. 1, 117-127 (2019).

22. Chen, Y. et al. Growth of $2 \mathrm{D} \mathrm{GaN}$ single crystals on liquid metals. J. Am. Chem. Soc. 140, 16392-16395 (2018).

23. Zavabeti, A. et al. A liquid metal reaction environment for the room-temperature synthesis of atomically thin metal oxides. Science 358, 332-335 (2017).

24. Sang, L., Liao, M. \& Sumiya, M. A comprehensive review of semiconductor ultraviolet photodetectors: from thin film to one-dimensional nanostructures. Sensors 13, 10482-10518 (2013).

25. Guo, D. et al. Review of $\mathrm{Ga}_{2} \mathrm{O}_{3}$-based optoelectronic devices. Mater. Today Phys. 11, 100157 (2019).

26. Balakrishnan, N. et al. Engineering $p-n$ junctions and bandgap tuning of InSe nanolayers by controlled oxidation. 2D Mater. 4, 025043 (2017)

27. Togo, A., Oba, F., Tanaka, I. \& Tatsumi, K. First-principles calculations of native defects in tin monoxide. Phys. Rev. B 74, 195128 (2006).

28. R, S., M, M. \& S, R. Optical properties of annealed tin (II) oxide in different ambients. Phys. Status Solidi A 136, 215-222 (1993).

29. Cabot, A., Arbiol, J., Ferré, R. \& Morante, J. R. Surface states in template synthesized tin oxide nanoparticles. J. Appl. Phys. 95, 2178-2180 (2004).

30. Sze, S. M. \& Ng, K. K. Physics of semiconductor devices, 3rd Ed., Wiley-Interscience (2007).

31. Zhou, C. et al. Self-driven metal-semiconductor-metal $\mathrm{WSe}_{2}$ photodetector with asymmetric contact geometries. Adv. Funct. Mater. 28, 1802954 (2018).

32. Zhu, H. et al. Metal-Oxide-Semiconductor-Structured MgZnO ultraviolet photodetector with high internal gain. J. Phys. Chem. C. 114, 7169-7172 (2010).

33. $\mathrm{Hu}, \mathrm{G}$. C. et al. High gain $\mathrm{Ga}_{2} \mathrm{O}_{3}$ solar-blind photodetectors realized via acarrier multiplication process. Opt. Express 23, 13554-13561 (2015).

34. An, Y. H. et al. Influence of oxygen vacancies on the photoresponse of $\beta-\mathrm{Ga}_{2} \mathrm{O}_{3} /$ SiC n-n type heterojunctions. J. Phys. D: Appl. Phys. 49, 285111 (2016).

35. Guo, D. Y. et al. Fabrication of $\beta-\mathrm{Ga}_{2} \mathrm{O}_{3} / \mathrm{ZnO}$ heterojunction for solar-blind deep ultraviolet photodetection. Semicond. Sci. Technol. 32, 03LT01 (2017).

36. Guo, X. C. et al. $\beta-\mathrm{Ga}_{2} \mathrm{O}_{3} / \mathrm{p}$-Si heterojunction solar-blind ultraviolet photodetector with enhanced photoelectric responsivity. J. Alloy. Compd. 660, 136-140 (2016).

37. Guo, D. et al. Fabrication of $\beta-\mathrm{Ga}_{2} \mathrm{O}_{3}$ thin films and solar-blind photodetectors by laser MBE technology. Opt. Mater. Express 4, 1067-1076 (2014).
38. $\mathrm{Li}$, Y. et al. Efficient assembly of bridged $\beta-\mathrm{Ga}_{2} \mathrm{O}_{3}$ nanowires for solar-blind photodetection. Adv. Funct. Mater. 20, 3972-3978 (2010).

39. Chen, $H$. et al. Ultrasensitive self-powered solar-blind deep-ultraviolet photodetector based on all-solid-state polyaniline/MgZnO bilayer. Small 12, 5809-5816 (2016).

40. Suzuki, R., Nakagomi, S., Kokubun, Y., Arai, N. \& Ohira, S. Enhancement of responsivity in solar-blind $\beta-\mathrm{Ga}_{2} \mathrm{O}_{3}$ photodiodes with a Au Schottky contact fabricated on single crystal substrates by annealing. Appl. Phys. Lett. 94, 222102 (2009).

41. Chen, Y. et al. 3D solar-blind $\mathrm{Ga}_{2} \mathrm{O}_{3}$ photodetector array realized via origam method. Adv. Funct. Mater. 29, 1906040 (2019).

42. Wang, $H$. et al. High responsivity and high rejection ratio of self-powered solarblind ultraviolet photodetector based on PEDOT:PSS $/ \mathrm{\beta}-\mathrm{Ga}_{2} \mathrm{O}_{3}$ organic/inorganic $\mathrm{p}-\mathrm{n}$ junction. J. Phys. Chem. Lett. 10, 6850-6856 (2019).

43. Kong, W.-Y. et al. Graphene- $\beta-\mathrm{Ga}_{2} \mathrm{O}_{3}$ heterojunction for highly sensitive deep UV photodetector application. Adv. Mater. 28, 10725-10731 (2016).

44. Lin, R. et al. High-performance graphene/ $/-\mathrm{Ga}_{2} \mathrm{O}_{3}$ heterojunction deep-ultraviolet photodetector with hot-electron excited carrier multiplication. ACS Appl. Mater. Interfaces 10, 22419-22426 (2018)

45. Kalra, A., Rathkanthiwar, S., Muralidharan, R., Raghavan, S. \& Nath, D. N. Materialto-device performance correlation for AlGaN-based solar-blind $\mathrm{p}-\mathrm{i}-\mathrm{n}$ photodiodes. Semicond. Sci. Technol. 35, 035001 (2020).

46. Jiang, K. et al. Polarization-enhanced AIGaN solar-blind ultraviolet detectors Photon. Res. 8, 1243-1252 (2020).

47. Liu, H. Y., Hou, F. Y. \& Chu, H. S. Mg0.35Zn0 ${ }_{65} \mathrm{O} / \mathrm{Al} / \mathrm{ZnO}$ photodetectors with capability of identifying ultraviolet-A/ultraviolet-B. IEEE Trans. Electron Devices 67, 2812-2818 (2020).

48. Li, Y. et al. Titania: Graphdiyne nanocomposites for high-performance deep ultraviolet photodetectors based on mixed-phase MgZnO. J. Alloy. Compd. 825, 153882 (2020).

49. Liu, Y. et al. Enhanced ultra-violet photodetection based on a heterojunction consisted of $\mathrm{ZnO}$ nanowires and single-layer graphene on silicon substrate. Electron. Mater. Lett. 16, 81-88 (2020).

50. Liu, D. et al. High-performance ultraviolet photodetector based on graphene quantum dots decorated $\mathrm{ZnO}$ nanorods/GaN film isotype heterojunctions. Nanoscale Res Lett. 13, 261 (2018).

51. Flemban, T. H. et al. A photodetector based on $\mathrm{p}-\mathrm{Si} / \mathrm{n}-\mathrm{ZnO}$ nanotube heterojunctions with high ultraviolet responsivity. ACS Appl. Mater. Interfaces 9 37120-37127 (2017).

52. Yao, J. D., Zheng, Z. Q., Shaoa, J. M. \& Yang, G. W. Stable, highly-responsive and broadband photodetection based on large-area multilayered $\mathrm{WS}_{2}$ films grown by pulsed-laser deposition. Nanoscale 7, 14974-14981 (2015).

53. Maculan, $\mathrm{G}$. et al. $\mathrm{CH}_{3} \mathrm{NH}_{3} \mathrm{PbCl}_{3}$ single crystals: inverse temperature crystallization and visible-blind UV-photodetector. J. Phys. Chem. Lett. 6, 3781-3786 (2015).

54. Zheng, W. et al. An ultrafast-temporally-responsive flexible photodetector with high sensitivity based on high-crystallinity organic-inorganic perovskite nanoflake. Nanoscale 9, 12718-12726 (2017).

\section{ACKNOWLEDGEMENTS}

This work was financially supported by the National Natural Science Foundation of China under Key Projects (Grant No. 91748206).

\section{AUTHOR CONTRIBUTIONS}

Q.L. and J.L. contributed equally to this work. Q.L. and J.L. conceived the project. Q.L. designed the experiments and fabricated the devices and performed the measurements with help from Ju.L. and T.-Y.L. All authors wrote the manuscript, discussed the results, and commented on the manuscript.

\section{COMPETING INTERESTS}

The authors declare no competing interests.

\section{ADDITIONAL INFORMATION}

Supplementary information The online version contains supplementary material available at https://doi.org/10.1038/s41699-021-00219-y.

Correspondence and requests for materials should be addressed to Q.L. or J.L.

Reprints and permission information is available at http://www.nature.com/ reprints 
Publisher's note Springer Nature remains neutral with regard to jurisdictional claims in published maps and institutional affiliations.

cc (i) Open Access This article is licensed under a Creative Commons adaptation, distribution and reproduction in any medium or format, as long as you give appropriate credit to the original author(s) and the source, provide a link to the Creative
Commons license, and indicate if changes were made. The images or other third party material in this article are included in the article's Creative Commons license, unless indicated otherwise in a credit line to the material. If material is not included in the article's Creative Commons license and your intended use is not permitted by statutory regulation or exceeds the permitted use, you will need to obtain permission directly from the copyright holder. To view a copy of this license, visit http://creativecommons. org/licenses/by/4.0/.

(c) The Author(s) 2021 